\title{
Intensity of treatment in Swiss cancer patients at the end-of-life
}

This article was published in the following Dove Press journal: Cancer Management and Research

\section{Caroline Bähler \\ Andri Signorell' \\ Eva Blozik',2 \\ Oliver Reich'}

'Department of Health Sciences, Helsana Insurance Group, Zürich, Switzerland; ${ }^{2}$ Department of Medicine, University Medical Centre Freiburg, Freiburg im Breisgau, Germany
Correspondence: Caroline Bähler Department of Health Sciences, Helsana Insurance Group, PO Box, 808I Zürich, Switzerland

Tel +4I 5834052 0I

Fax +4I 583400434

Email caroline.baehler-baumgartner@ helsana.ch
Purpose: Current evidence on the care-delivering process and the intensity of treatment at the end-of-life of cancer patients is limited and remains unclear. Our objective was to examine the care-delivering processes in health care during the last months of life with real-life data of Swiss cancer patients.

Patients and methods: The study population consisted of adult decedents in 2014 who were insured at Helsana Group. Data on the final cause of death were provided additionally by the Swiss Federal Statistical Office. Of the 10,275 decedents, 2,710 (26.4\%) died of cancer Intensity of treatment and health care utilization (including transitions) at their end-of-life were examined. Intensity measures included the following: last dose of chemotherapy within 14 days of death, a new chemotherapy regimen starting $<30$ days before death, more than one hospital admission or spending $>14$ days in hospital in the last month, death in an acute care hospital, more than one emergency visit and $\geq 1$ intensive care unit admission in the last month of life. Results: In the last 6 months of life, $89.5 \%$ of cancer patients had $\geq 1$ transition, with $87.2 \%$ being hospitalized. Within 30 days before death, $64.2 \%$ of the decedents had $\geq 1$ intensive treatment, whereby $8.9 \%$ started a new chemotherapy. In the multinomial logistic regression model, older age, higher density of nursing home beds and home care nurses were associated with a decrease, while living in the Italian- or French-speaking part of Switzerland was associated with an increase in intensive care.

Conclusion: Swiss cancer patients insured by Helsana Group experience a considerable number of transitions and intensive treatments at the end-of-life, whereby treatment intensity declines with increasing age. Among others, increased home care nursing might be helpful to reduce unwarranted treatments and transitions, therefore leading to better care at the end-of-life.

Keywords: cancer, end-of-life care, health care costs, transitions, intensity of treatment, health insurance, regional variation

\section{Introduction}

Cancer is the second most common cause of death in Switzerland. In 2014, >16,000 (26\%) of all decedents died of cancer. ${ }^{1}$ In 12 European Union countries, cancer was shown to have overtaken cardiovascular diseases as the leading cause of death. ${ }^{2}$ Nowadays, modern medicine provides many treatment options for patients with cancer and it is often believed that cancer patients undergo numerous treatments up until old age at the end-of-life. Findings by Earle et al revealed that $30 \%$ of elderly decedents had at least one indicator of intensive care (i.e., chemotherapy) at the end-of-life when measured by means of claims-based data. ${ }^{3}$ Previous studies have also found an increase in the use of intensive cancer care at the end-of-life. ${ }^{3,4}$ According to a more 
recent review by Langton et al, almost $40 \%$ of mainly elderly patients received chemotherapy or life-sustaining interventions in their last month of life. ${ }^{5}$ But some of these treatment options might not be advisable for cancer patients at their end-of-life. Physicians, patients as well as their relatives are, therefore, confronted with difficult decisions whether or not to provide (further) treatments at the end-of-life. ${ }^{6}$ Thereby, more intensive care was not always regarded as better care. ${ }^{7}$ In addition, studies have shown that early use of palliative care may, among others, result in prolonged life expectancy and less pain in dying patients. ${ }^{8-10}$

Earlier studies have found considerable variations concerning chemotherapy and radiotherapy treatment at the end-of-life in cancer patients. ${ }^{3,11}$ The number of transitions between care settings also differed considerably between regions in Switzerland in the last 6 months before death. ${ }^{12}$ While some differences in the intensity of treatment at the end-of-life certainly are justified, others might indicate overuse or underuse of treatment options in particular regions or subgroups. ${ }^{13,14}$ The availability of health care services may play an important role: decedents who resided in regions with a higher availability of hospice services were shown to receive less intensive care at the end-of-life. ${ }^{3}$ However, little is known in Switzerland about the care of cancer patients at the end-of-life. Previous research mainly concentrated on chemotherapy, radiotherapy and hospitalizations in the last 30 days of life. ${ }^{11,15,16}$ A large study of four European countries regarding the health care utilization and the care setting transitions in the last 3 months of life of cancer patients did not include Swiss patients. ${ }^{17}$ Knowledge in the field of health care utilization at the end-of-life is decisive not only for health care providers but also for cancer patients and their relatives.

\section{Study aims}

This study aimed to examine the care-delivering processes in health care during the last months of life with real-life data of Swiss cancer patients. Age differences in the intensity of treatment, using established criteria, as well as in health care utilization (including transitions) were examined, thereby accounting for a variety of individual and regional factors. ${ }^{3}$ Our goal was to establish clarity on whether differences in the intensity of care between regions or patient groups exist, and if so, to what extent. The indicators for intensity cannot judge the quality of care provided to cancer patients, but can be used as red flags to identify regions or groups with potential challenges concerning the coordination of care at the endof-life. The identification of such differences is the first step in addressing possible overuse or underuse. Former research has shown that it is feasible to assess intensity of care at the end-of-life using routine claims and further administrative databases..$^{3,7,18-20}$

\section{Patients and methods Study population}

Helsana is one of the largest health insurers in Switzerland and covered almost one-fifth of all decedents in Switzerland in 2014. The study population consists of a retrospective cohort of decedents in 2014 who were insured by Helsana Insurance Group, and of whom data on the last year of life were available. Further, data on the final cause of death of the decedents were provided by the Swiss Federal Statistical Office and merged with insurance claims data.

A total of 11,356 adult decedents were included in the Helsana population. Of these, 599 (5.3\%) were excluded due to lack of detailed information on health care utilization (i.e., decedents living abroad, or lump sums used for reimbursement in nursing home residents), and 482 (4.2\%) were excluded due to unknown cause of death or inability to merge the two datasets. Finally, 10,275 decedents of the year 2014 were included, of whom 2,710 (26.4\%) died of cancer (or its complications at an early stage).

A previous study examining the representativeness of the database found that the Helsana population was slightly older than the average Swiss population. ${ }^{21}$ But due to the geographical diversity covered by the Helsana database, the study contains information of a variety of cultural, social, regional and otherwise divergent populations.

As this study is retrospective and based on anonymized routine administrative health care claims data, a patient informed consent was not needed, according to the national ethical and legal regulation (article 22 of the Swiss data protection law). Furthermore, a formal request was sent to the Ethics committee Kantonale Ethikkommission Zürich in the Canton of Zurich. According to this committee, no further ethics approval was needed as the study falls outside the scope of the Swiss Federal Act on Research involving Human Beings (Human Research Act).

\section{Measures}

Cancer patients were defined as those decedents whose underlying cause of death was cancer. Based on the study by Earle et al, ${ }^{3}$ intensity of care at the end-of-life was defined as the occurrence of any of the following indicators: 1) last dose of chemotherapy within 14 days of death, 2) a new chemotherapy regimen starting $<30$ days before death, 3) more than one emergency visit in the last month of life, 4) more than 
one hospital admission or spending $>14$ days in hospital in the last month of life, 5) death in an acute care hospital and 6) at least one intensive care unit (ICU) admission in the last month of life. These indicators of the intensity of end-of-life cancer care were derived from administrative data such as claims data, and were identified by focus groups with cancer patients and family members as well as with expert panels. ${ }^{22}$ An emergency visit was counted only if the patient spent at least $1 \mathrm{~h}$ in the ICU. For the purpose of multivariate analysis, the number of intensive treatments at the end-of-life was divided into three groups: 0,1 and 2+ treatment(s).

Additionally, transitions (defined as a change in the health care setting as identified by the claims data ${ }^{23}$ ) and the place of death (hospital, nursing home, home/others) were analyzed. The number of transitions between health care settings (hospital, nursing home, home/others) and the proportion of decedents with burdensome transitions, as defined by Teno et $\mathrm{al},{ }^{23}$ were calculated. A burdensome transition was defined as three or more hospitalizations in the last 90 days of life, or at least one transition in the last 3 days of life. ${ }^{23}$ Health care utilization also comprised the proportion of decedents with at least one hospitalization and the median number of days in hospital, as well as the proportion of decedents with at least one nursing home admission with the median length of stay. Furthermore, the number of physician visits by primary care physicians and specialists is shown.

The following variables concerning patient characteristics were considered: age, sex, cause of death, number of chronic conditions, health insurance plan, as well as regional covariates: language region, community characters (urban vs. rural), the cantonal density of hospital beds (ranging from 1.8 to 11.5 per 1,000 inhabitants), the cantonal density of nursing home beds (ranging from 48.3 to 120.9 per 1,000 inhabitants aged 65 years and older), as well as the density of home care nurses (ranging from 1.4 to 3.8 per 1,000 inhabitants) and ambulatory care physicians on the cantonal level (ranging from 92 to 425 per 100,000 inhabitants). Data on the final cause of death of the decedents were provided by the Swiss Federal Statistical Office. The merging was performed on the premises of the Swiss Federal Statistical Office using only few predefined key variables, excluding the name and address. Chronic conditions were identified based on the Anatomical Therapeutic Chemical classification system, using an updated measure of the Pharmacy-based Cost Group model by Huber et al. ${ }^{24}$ The following 22 chronic conditions were distinguished: acid-related disorders, bone diseases (osteoporosis), cancer, cardiovascular diseases (including hypertension), dementia, diabetes mellitus, epilepsy, glaucoma, gout/hyperuricemia, human immunodeficiency virus, hyperlipidemia, intestinal inflammatory diseases, iron-deficiency anemia, migraines, pain, Parkinson's disease, psychological disorders (sleep disorders, depression), psychoses, respiratory illness (asthma, COPD), rheumatologic conditions, thyroid disorders, tuberculosis.

\section{Statistical analysis}

Population characteristics, health care utilization, as well as transitions between health care settings in cancer patients in the last 6 months of life were assessed and compared to those dying of other causes by means of descriptive statistics. Data are presented as percentages for categorical variables and as medians and interquartile ranges (IQRs; presented as the first and the third quartiles) for continuous variables.

Intensive treatments for the end-of-life in patients who died of cancer were assessed. Age differences regarding the intensity of cancer treatment are presented using boxplots. Multinomial logistic regression analysis was performed to determine the impact of individual and regional variables on the odds of intensive cancer treatments at the end-of-life. ${ }^{25}$ Odds ratios (ORs) are shown for the three groups of intensive treatments: 0,1 and 2 or more treatments. A threshold for statistical significance of $p=0.05$ (two sided) was utilized. Because hospice use cannot be identified by means of the present data, a sensitivity analysis was carried out to examine health care utilization and treatment intensity in cancer decedents, thereby excluding the cancer decedents who lived in 4 out of 26 cantons with hospice availability (Aargau, Luzern, Zürich and Schwyz). ${ }^{26}$ All analyses were carried out using R statistics, version 3.2.0 (R Foundation for Statistical Computing, Vienna, Austria).

\section{Results}

The median (IQR) age of the total analytic sample of 10,275 decedents was 84 (75-90) years, and almost 53\% were women. The distribution of the decedents in different age groups was as follows: $453(16.7 \%)$ of the cancer decedents were aged $18-64$ years, $716(26.4 \%)$ were aged $65-74$ years, $908(33.5 \%)$ were aged $75-84$ years and $633(23.4 \%)$ of the cancer decedents were aged 85 years and older. In non-cancer decedents, the distribution was as follows: 595 (7.9\%) were aged 18-64 years, $710(9.4 \%)$ were aged $65-74$ years, 2, 025 (26.8\%) were aged $75-84$ years and 4,235 (56.0\%) of the decedents were aged 85 years and older. The characteristics of the study population are presented in Table 1. Cancer decedents were on average younger and they more often lived in the Italian part of Switzerland and in rural areas compared with decedents dying of other causes. Furthermore, they more often had supplementary hospital insurance and higher deductibles, although differences in the latter were rather small. The main causes of death of those not dying of cancer 
Table I Characteristics of the study population $(\mathrm{N}=10,275)$

\begin{tabular}{|c|c|c|c|c|}
\hline $\begin{array}{l}\text { Characteristics of study } \\
\text { population }\end{array}$ & Total & $\begin{array}{l}\text { Decedents } \\
\text { dying of cancer }\end{array}$ & $\begin{array}{l}\text { Decedents dying } \\
\text { of other causes }\end{array}$ & $p$-value \\
\hline $\mathrm{n}$ & 10,275 & $2,710(26.4 \%)$ & 7,565 (73.6\%) & \\
\hline Female sex & $5,412(52.7 \%)$ & $\mathrm{I}, 228(45.3 \%)$ & 4,184 (55.3\%) & $<0.001$ \\
\hline Age, years, median (IQR) & $84.0(75-90)$ & $77.0(68-84)$ & $86.0(79-91)$ & $<0.001$ \\
\hline Language area & & & & $<0.001$ \\
\hline German & $8,199(79.8 \%)$ & $2,114(78.0 \%)$ & $6,085(80.4 \%)$ & \\
\hline French & I,598 (I5.6\%) & $423(15.6 \%)$ & $\mathrm{I}, 175$ (I5.5\%) & \\
\hline Italian & $478(4.7 \%)$ & $173(6.4 \%)$ & $305(4.0 \%)$ & \\
\hline Type of residence (urban area) & $3,312(32.2 \%)$ & $797(29.4 \%)$ & $2,515(33.2 \%)$ & $<0.001$ \\
\hline Chronic conditions, median (IQR) & $4.0(3.0-6.0)$ & $5.0(3.0-6.0)$ & $4.0(2.0-5.0)$ & $<0.001$ \\
\hline Managed care & $3,190(31.0 \%)$ & 1,017 (37.5\%) & $2,173(28.7 \%)$ & $<0.001$ \\
\hline Supplementary hospital insurance & 2,031 (19.8\%) & $617(22.8 \%)$ & I,4l4 (I8.7\%) & $<0.001$ \\
\hline Higher deductible (>CHF 500) & $599(5.8 \%)$ & 191 (7.0\%) & $408(5.4 \%)$ & 0.002 \\
\hline
\end{tabular}

Notes: $p$-values, assigning the differences between the decedents dying of cancer vs. dying of other causes, were calculated using Fisher's exact test for dichotomous variables, Wilcoxon rank sum test for continuous variables and chi-squared test for categorical variables. Rhaeto-Romanic area is assigned to the German area.

Abbreviation: IQR, interquartile range (presented as the first and the third quartiles).

Table 2 Cause of death by cancer type and sex $(n=2,710)$

\begin{tabular}{llll}
\hline Type of cancer & Men, n (\%) & Women, n (\%) & Total, n (\%) \\
\hline Lung cancer & $318(21.5)$ & $184(15.0)$ & $502(18.5)$ \\
Colorectal cancer & $138(9.3)$ & $12 I(9.9)$ & $259(9.6)$ \\
Hematologic cancer & $125(8.4)$ & $115(9.4)$ & $240(8.9)$ \\
Prostate cancer & $236(15.9)$ & & $236(8.7)$ \\
Breast cancer & & $212(17.3)$ & $212(7.8)$ \\
Pancreas cancer & $85(5.7)$ & $103(8.4)$ & $188(6.9)$ \\
Other cancer types & $580(39.1)$ & $493(40.1)$ & $1,073(39.6)$ \\
\hline
\end{tabular}

were diseases of the circulatory system (29.0\%), followed by mental, behavioral and neurodevelopmental disorders $(8.2 \%)$, stroke $(6.3 \%)$, diseases of the respiratory system $(6.0 \%)$ and diseases of the nervous system (5.3\%). Cancer decedents most frequently died of lung cancer (18.5\%), followed by colorectal cancer $(9.6 \%)$ and hematologic cancer $(8.9 \%)$. The frequencies of cancer types as the main cause of death, separately for men and women, are shown in Table 2.

Overall, $89.5 \%$ of the cancer decedents were transferred at least once in the last 6 months of life, compared with $58.7 \%$ of the decedents dying from other causes, whereby $87.2 \%$ of cancer decedents and $54.3 \%$ of non-cancer decedents were hospitalized (Table 3). Nearly one-fifth of patients dying of cancer and only about 1 in 10 patients not dying of cancer had at least one burdensome transition (defined as three or more hospitalizations in the last 90 days of life, or at least one transition in the last 3 days of life). The median number of acute hospital admissions was twice as high in cancer decedents ( 2 vs. $1 ; p<0.001)$. The number of consultations by specialists was substantially higher in cancer decedents, whereas no differences were found in the number of primary care physician consultations. Almost $60 \%$ of cancer dece- dents died in the hospital, whereas decedents dying of other causes most frequently died in nursing homes.

Looking at cancer decedents, almost $65 \%$ had at least one intensive treatment (as defined by Earle et $\mathrm{al}^{3}$ ) at the end-oflife, whereby the number of intensive treatments decreased with increasing age (Figure 1). Altogether, $35.8 \%$ of cancer decedents had none, $23.8 \%$ had one and $40.4 \%$ had two and more intensive cancer treatment(s). The median (IQR) number of intensive treatments was $2.0(1.0-2.0)$ in the youngest and $0.0(0.0-1.0)$ in the oldest age group $(p<0.001)$. In contrast, no statistically significant sex-specific differences were found.

The proportions of patients with a specific intensive treatment varied markedly (Table 4). The proportion of decedents was highest in the youngest age group and lowest in the oldest age group for all intensive treatments. Variations between language areas were found for all intensive treatments except for starting a new chemotherapy regimen in the last month of life and more than one emergency visit in the last month of life. Receiving a last dose of chemotherapy within 14 days of death, in-hospital death and ICU admission(s) more frequently occurred in the Italian-speaking part of Switzerland, while a higher proportion of patients with more than one hospital admission or spending $>14$ days in hospital in the last month of life was found in the French-speaking regions.

In the multinomial regression model, decedents in the French or Italian part of Switzerland had a 2.4 times higher odds for $2+$ intensive treatments compared with cancer decedents in the German part (Table 5). Moreover, each increase in the density of hospital beds was associated with a 1.14 higher odds for $2+$ treatments. In contrast, each increase in the density of home care nurses or nursing home beds was associated with a 17.4 and a 1.3 lower odds for one intensive 
Table 3 Health care utilization of decedents dying of cancer vs. dying of other causes in their last 6 months of life $(N=10,275)$

\begin{tabular}{|c|c|c|c|c|}
\hline Health care use & Total & $\begin{array}{l}\text { Decedents dying } \\
\text { of cancer }\end{array}$ & $\begin{array}{l}\text { Decedents dying } \\
\text { of other causes }\end{array}$ & $p$-value \\
\hline$n(\%)$ & 10,275 & $2,710(26.4)$ & $7,565(73.6)$ & \\
\hline Individuals with at least one transition & $6,867(66.8)$ & $2,425(89.5)$ & $4,442(58.7)$ & $<0.001$ \\
\hline Number of transitions, ${ }^{a}$ median (IQR) & $2.0(I-4)$ & $3.0(1-5)$ & $2.0(1-3)$ & $<0.001$ \\
\hline Individuals with burdensome transition(s) & $I, 34 \mid(\mid 3.1)$ & $450(16.6)$ & $891(11.8)$ & $<0.001$ \\
\hline Individuals with hospitalization(s) & $6,472(63.0)$ & $2,364(87.2)$ & $4,108(54.3)$ & $<0.001$ \\
\hline Length of stay, ${ }^{\mathrm{a}}$ median (IQR) & $35.0(|3-9|)$ & $31.0(16-61)$ & $38.0(11-137)$ & $<0.001$ \\
\hline Individuals with nursing home admission(s) & $4,686(45.6)$ & $743(27.4)$ & $3,943(52.1)$ & $<0.001$ \\
\hline Length of stay, ${ }^{a}$ median (IQR) & $176.0(80-181)$ & $66.0(20-170)$ & $179.0(|27-18|)$ & $<0.001$ \\
\hline Individuals with consultation(s) & $9,816(95.5)$ & $2,670(98.5)$ & $7,146(94.5)$ & $<0.001$ \\
\hline Number of consultations, ${ }^{a}$ median (IQR) & $12.0(6-20)$ & $19.0(11-29)$ & $10.0(5-16)$ & $<0.001$ \\
\hline By primary care physicians & $6.0(2-11)$ & $6.0(2-11)$ & $6.0(2-10)$ & NS \\
\hline By specialists & $3.0(1-10)$ & II.0 (3-2I) & $2.0(0-6)$ & $<0.001$ \\
\hline Place of death & & & & $<0.001$ \\
\hline Home & $2,269(22.1)$ & $559(20.6)$ & $1,710(22.6)$ & \\
\hline Hospital & $4,133(40.2)$ & $1,546(57.0)$ & $2,587(34.2)$ & \\
\hline Nursing home & $3,873(37.7)$ & $605(22.3)$ & $3,268(43.2)$ & \\
\hline
\end{tabular}

Notes: $p$-values, assigning the differences between the decedents dying of cancer vs. of other causes, were calculated using Fisher's exact test for dichotomous variables, Wilcoxon rank sum test for continuous variables and chi-squared test for categorical variables. aln decedents with at least one admission, transition or consultation, respectively.

Abbreviations: IQR, interquartile range (presented as the first and the third quartiles); NS, not significant.

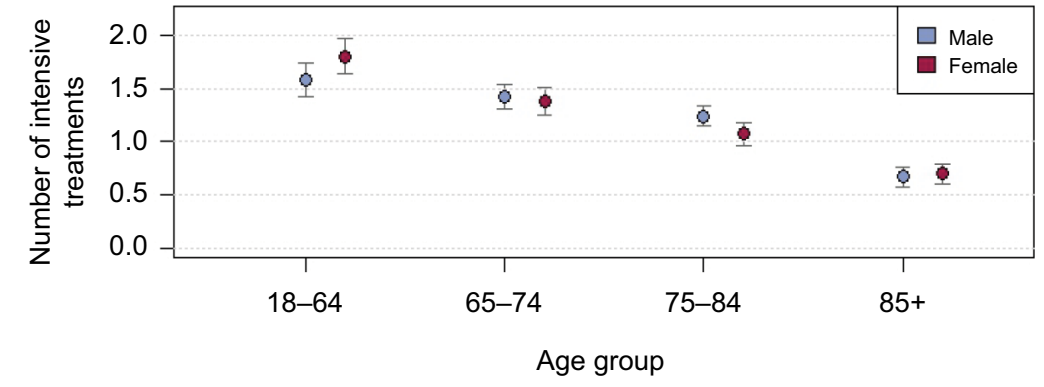

Figure I Mean number of intensive treatments at the end-of-life, divided by sex and age group $(n=2,7 / 0)$.

Table 4 Proportions of cancer decedents with intensive treatments at the end-of-life by age group $(n=2,710)$

\begin{tabular}{|c|c|c|c|c|c|c|}
\hline \multirow[t]{2}{*}{ Intensive treatment } & \multicolumn{5}{|l|}{ Age in years } & \multirow[t]{2}{*}{$p$-value } \\
\hline & $\begin{array}{l}\text { Total } \\
(n=2,7 \mid 0)\end{array}$ & $\begin{array}{l}18-64 \\
(n=453)\end{array}$ & $\begin{array}{l}65-74 \\
(n=716)\end{array}$ & $\begin{array}{l}75-84 \\
(n=908)\end{array}$ & $\begin{array}{l}85+ \\
(n=633)\end{array}$ & \\
\hline Last dose of chemotherapy within I 4 days of death & 199 (7.3\%) & $63(13.9 \%)$ & 75 (10.5\%) & $52(5.7 \%)$ & $9(1.4 \%)$ & $<0.001$ \\
\hline $\begin{array}{l}\text { Starting a new chemotherapy regimen } \leq 30 \text { days before } \\
\text { death }\end{array}$ & $242(8.9 \%)$ & $73(16.1 \%)$ & $88(12.3 \%)$ & 70 (7.7\%) & II (I.7\%) & $<0.001$ \\
\hline More than one emergency visit in the last month of life & $56(2.1 \%)$ & $18(4.0 \%)$ & $12(1.7 \%)$ & $21(2.3 \%)$ & $5(0.8 \%)$ & 0.003 \\
\hline $\begin{array}{l}\text { More than one hospital admission or spending }>14 \text { days } \\
\text { in hospital in the last month of life }\end{array}$ & I,053 (38.9\%) & $237(52.3 \%)$ & $321(44.8 \%)$ & $345(38.0 \%)$ & $150(23.7 \%)$ & $<0.001$ \\
\hline Spending $>14$ days in hospital in the last month of life & $976(36.0 \%)$ & $213(47.0 \%)$ & $295(41.2 \%)$ & $330(36.3 \%)$ & $138(21.8 \%)$ & $<0.001$ \\
\hline $\begin{array}{l}\text { More than one hospital admission in the last month of } \\
\text { life }\end{array}$ & $174(6.4 \%)$ & $47(10.4 \%)$ & $58(8.1 \%)$ & $47(5.2 \%)$ & $22(3.5 \%)$ & $<0.001$ \\
\hline Death in an acute care hospital & $\mathrm{I}, 522(56.2 \%)$ & $323(71.3 \%)$ & $464(64.8 \%)$ & $504(55.5 \%)$ & $23 \mathrm{I}(36.5 \%)$ & $<0.001$ \\
\hline At least one ICU admission in the last month of life & 187 (6.9\%) & $46(10.2 \%)$ & $48(6.7 \%)$ & $68(7.5 \%)$ & $25(3.9 \%)$ & $<0.001$ \\
\hline
\end{tabular}

Note: $p$-values, assigning the differences between the different age groups, were calculated using chi-squared test.

Abbreviation: ICU, intensive care unit. 
treatment, and a 15.5 and a 1.1 lower odds for $2+$ intensive treatments in cancer patients, respectively. As found previously, older age was substantially associated with lower odds of one or two or more intensive treatments compared with their younger counterparts. Patients with a higher number of chronic conditions were also less likely to undergo two or more treatments. The type of cancer also had a significant impact on the intensity of treatment: intensive care was generally more likely in patients with lung cancer and less likely in patients with prostate cancer.

In the subpopulation of cancer decedents who lived in a canton without hospice availability, 1,159(69.1\%) of the
1,677 cancer patients had at least one intensive treatment at the end-of-life, $90.2 \%$ were transferred at least once in the last 6 months of life, whereby $88.7 \%$ were hospitalized. Sixty-one percent of patients died in an acute care hospital. In contrast, $64.2 \%$ of the cancer decedents from the total study population had at least one intensive treatment and $89.5 \%$ had at least one transition, with $87.2 \%$ being hospitalized during the corresponding time span. Also, $56.2 \%$ of the cancer patients died in an acute care hospital. Table 6 shows the proportions of cancer decedents of the subpopulation with intensive treatments at the end-of-life by age group.

Table 5 Multinomial logistic regression model on intensive cancer treatment groups ${ }^{\mathrm{a}}$

\begin{tabular}{|c|c|c|c|c|}
\hline \multirow[t]{2}{*}{ Predictors } & \multicolumn{4}{|c|}{ Intensive cancer treatment group } \\
\hline & Group I, OR & $95 \% \mathrm{Cl}$ & Group 2, OR & $95 \% \mathrm{Cl}$ \\
\hline Age (in years) & 0.973 & $0.964-0.982$ & 0.945 & $0.937-0.954$ \\
\hline Sex (females) & 0.939 & $0.748-1.180$ & 0.922 & $0.75 I-I .130$ \\
\hline \multicolumn{5}{|l|}{ 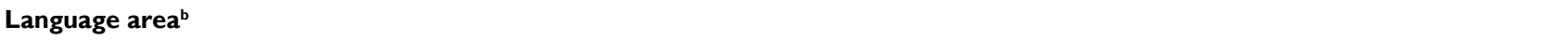 } \\
\hline German & 1.000 & & 1.000 & \\
\hline French & 1.224 & $0.835-1.795$ & 2.419 & $1.733-3.377$ \\
\hline Italian & 1.522 & $0.888-2.607$ & $2.35 \mathrm{I}$ & $1.46 \mathrm{I}-3.783$ \\
\hline Density of nursing home beds & 0.987 & $0.975-0.998$ & 0.989 & $0.979-0.999$ \\
\hline Density of hospital beds & 0.993 & $0.880-1.120$ & 1.139 & $1.027-1.264$ \\
\hline Density of home care nurses & 0.826 & $0.685-0.996$ & 0.845 & $0.714-0.999$ \\
\hline Density of ambulatory care physicians & 1.000 & $0.998-1.003$ & 0.999 & $0.996-1.001$ \\
\hline \multicolumn{5}{|l|}{ Cancer group } \\
\hline Colorectal cancer & 1.000 & & 1.000 & \\
\hline Hematologic cancer & 1.178 & $0.723-1.917$ & 1.431 & $0.938-2.182$ \\
\hline Lung cancer & 1.640 & I.085-2.478 & 1.314 & $0.907-1.903$ \\
\hline Breast cancer & 1.216 & $0.746-1.982$ & 0.674 & $0.423-1.073$ \\
\hline Pancreas cancer & 0.947 & $0.562-1.595$ & 1.045 & $0.667-1.636$ \\
\hline Prostate cancer & 0.756 & $0.467-1.224$ & 0.569 & $0.365-0.885$ \\
\hline Other cancer types & 1.098 & $0.759-1.590$ & 0.991 & $0.715-1.373$ \\
\hline Number of chronic conditions & 0.983 & $0.936-1.032$ & 0.930 & $0.890-0.972$ \\
\hline
\end{tabular}

Notes: Statistically significant differences are presented in bold. ${ }^{a}$ Group I = one intensive treatment $(n=644)$; Group $2=$ two or more intensive treatments ( $\left.\mathrm{n}=\mathrm{I}, 059\right)$. ${ }^{\mathrm{b}}$ Rhaeto-Romanic area is assigned to the German area.

Abbreviation: OR, odds ratio.

Table 6 Proportions of cancer decedents with intensive treatments at the end-of-life by age group, whereby cancer decedents who lived in one of the four cantons with hospice availability were excluded $(n=I, 677)$

\begin{tabular}{|c|c|c|c|c|c|c|}
\hline \multirow[t]{2}{*}{ Intensive treatment } & \multicolumn{5}{|l|}{ Age in years } & \multirow[t]{2}{*}{ p-value } \\
\hline & $\begin{array}{l}\text { Total } \\
(n=I, 677)\end{array}$ & $\begin{array}{l}18-64 \\
(n=280)\end{array}$ & $\begin{array}{l}65-74 \\
(n=464)\end{array}$ & $\begin{array}{l}75-84 \\
(n=562)\end{array}$ & $\begin{array}{l}85+ \\
(n=37 I)\end{array}$ & \\
\hline Last dose of chemotherapy within 14 days of death & $128(7.6 \%)$ & 35 (12.5\%) & 52 (II.2\%) & $35(6.2 \%)$ & $6(1.6 \%)$ & $<0.001$ \\
\hline $\begin{array}{l}\text { Starting a new chemotherapy regimen } \leq 30 \text { days before } \\
\text { death }\end{array}$ & $154(9.2 \%)$ & $43(15.4 \%)$ & $56(12.1 \%)$ & $48(8.5 \%)$ & $7(1.9 \%)$ & $<0.001$ \\
\hline More than one emergency visit in the last month of life & $35(2.1 \%)$ & II (3.9\%) & $9(1.9 \%)$ & $14(2.5 \%)$ & I (0.3\%) & 0.010 \\
\hline $\begin{array}{l}\text { More than one hospital admission or spending }>14 \text { days } \\
\text { in hospital in the last month of life }\end{array}$ & $724(43.2 \%)$ & $155(55.4 \%)$ & $227(48.9 \%)$ & $240(42.7 \%)$ & $102(27.5 \%)$ & $<0.001$ \\
\hline Spending $>14$ days in hospital in the last month of life & $675(40.3 \%)$ & $138(49.3 \%)$ & $2 \mathrm{II}(45.5 \%)$ & $231(41.1 \%)$ & $95(25.6 \%)$ & $<0.001$ \\
\hline More than one hospital admission in the last month of life & $112(6.7 \%)$ & $30(10.7 \%)$ & $39(8.4 \%)$ & $31(5.5 \%)$ & $12(3.2 \%)$ & $<0.001$ \\
\hline Death in an acute care hospital & $\mathrm{I}, 023(6 \mathrm{I} .0 \%)$ & $211(75.4 \%)$ & $324(69.8 \%)$ & $331(58.9 \%)$ & $157(42.3 \%)$ & $<0.001$ \\
\hline At least one ICU admission in the last month of life & $116(6.9 \%)$ & $32(11.4 \%)$ & $32(6.9 \%)$ & $40(7.1 \%)$ & $12(3.2 \%)$ & $<0.001$ \\
\hline
\end{tabular}

Note: $p$-values, assigning the differences between the different age groups, were calculated using chi-squared test.

Abbreviation: ICU, intensive care unit. 


\section{Discussion}

This is the first study exploring detailed patient-relevant dimensions of treatment intensity for cancer patients at the end-of-life in a real-life Swiss population. It reveals that the intensity of treatment and the number of transitions are high in cancer patients.

According to our findings, almost $65 \%$ of Swiss cancer decedents had at least one intensive treatment at the end-oflife. This proportion is higher compared with the findings from studies conducted considerably earlier in other health care settings and cultural contexts. Only $30 \%$ of all decedents had at least one indicator of intensive care in the US study by Earle et $\mathrm{al}^{3}$ conducted in 1993-1996. However, they found an increase in the intensity of treatment within the observed time span. Ho et $\mathrm{al}^{4}$ stated that $22.4 \%$ of Canadian adults with a cancer cause of death experienced at least one incident of potentially aggressive cancer care at the end-of-life. However, some of the treatments such as death in an acute hospital, which was shown to be frequent in our cohort, were not considered in their definition of potentially aggressive cancer care and, thus, explains the higher rate of intensive treatment in this study. Including only these four indicators for potentially aggressive cancer care, as used by Ho et al, ${ }^{4}$ in our analysis would result in a proportion of $18.0 \%$ of cancer patients with at least one intensive treatment at the end-of-life.

In our study, $56 \%$ of the cancer patients died in an acute hospital. This is widely in line with the literature. In an international cohort study using administrative and registry data of 2010 on health care utilization at the end-of-life, high proportions of cancer patients dying in acute hospitals were found in Belgium (51.2\%), Canada (52.1\%), England (41.7\%), Germany (38.3\%) and Norway (44.7\%), when compared with the USA (22.2\%) and the Netherlands (29.4\%). ${ }^{27}$ The low rate in the USA might be due to the high pressure on costs forcing patients to move from hospitals to hospices or nursing homes, as well as to the high level of hospice capacity. In Taiwan, almost two-thirds of the cancer patients died in an acute care hospital. ${ }^{28}$ According to a mortality follow-back study in London, dying at home was associated with more peace for decedents in their last week of life and with less grief in their relatives, but preceding discussions about patients' preferences are needed. ${ }^{29}$ Moreover, this high proportion of hospital deaths is contrary to what the Swiss policy was seeking and to what patients prefer according to a representative Swiss survey. ${ }^{30}$

Our findings revealed that about $7 \%$ of the decedents received a last dose of chemotherapy within 14 days of death and nearly $9 \%$ started a new chemotherapy regimen within 30 days of death. In the review by Langton et al, ${ }^{5}$ chemotherapy was delivered to $1 \%-19 \%$ of patients in the last 14 days. In the retrospective Canadian study, chemotherapy was administered to $2.4 \%-4.8 \%$ of decedents in the last 2 weeks of life. ${ }^{31}$ However, in this latter study, only intravenous administration of chemotherapy could be considered. In the study by Earle et al, ${ }^{3} 5.7 \%$ of the decedents received a new chemotherapy within 30 days of death. This is comparable to $7.5 \%$ of elderly patients (65 years and older) receiving a new chemotherapy in our cohort. In Portuguese patients with advanced solid tumors, $14 \%$ started a new chemotherapy regimen within 30 days of death. ${ }^{32}$ In a prospective US study, the use of chemotherapy at the end-of-life was associated with an increased risk of cardiopulmonary resuscitation, mechanical ventilation and dying in an ICU rather than in their preferred place of death. ${ }^{33}$

Almost $40 \%$ of the patients in our cohort spent $>14$ days in the hospital and roughly $6 \%$ had multiple hospital admissions in the last month of life. These results correspond to findings from Taiwan, where $46.2 \%$ spent $>14$ days in the hospital and 13.6\% had multiple hospital admissions during their last month of life. ${ }^{28}$ In the study by Earle et al, ${ }^{3}$ only $11.6 \%$ spent $>14$ days in the hospital in the last month of life, but the proportion of patients with more than one acute hospital admission is comparable $(9.1 \%)$. Due to long hospital stays in many patients of our cohort, the odds for readmissions were lower. According to our analyses, 6.9\% had at least one ICU admission and $2.1 \%$ had more than one emergency visit in the last month. ICU admission during the same time span was seen in $3.5 \%-27.2 \%$ of cancer patients, and emergency visits were found in $9.2 \%-57.6 \%$ of patients in previous findings. ${ }^{3,27,28,34}$ Patients who spent $<1 \mathrm{~h}$ in the ICU were regarded as not having an admission to the ICU in our study. This might have led to an underestimation of the number of decedents with at least one ICU admission.

In sum, intensive care at the end-of-life assessed by means of claims data is frequent in Switzerland, but varies broadly across regions because of different health care systems, health care professionals involved in the care of those patients as well as due to different cultural settings. While some of these treatments are certainly fully appropriate and in accordance with patient preferences, others might be the result of a lack of coordination or good communication, or the density parameters of health care providers.

We identified important differences according to the factors associated with treatment intensity that are assumingly not directly linked with the patients' characteristics, such as 
diagnosis. Specifically, the density of ambulatory health care providers as well as the density of the health care institutions seemed to have an important impact on the cancer treatment at the end-of-life. A high density of nursing home beds and a high density of home care nurses were both associated with a lower likelihood of having one and two or more intensive treatments at the end-of-life, respectively. In contrast, a high density of hospital beds was related to more intensive treatment. Albeit, it needs to be considered that the $\mathrm{CI}$ in the latter association between the density of nursing home beds and intensive treatments is relatively wide and must therefore be interpreted with caution. Similar associations between treatment intensity and density of health care providers and infrastructure at the end-of-life were found in an earlier study conducted in Switzerland, ${ }^{12}$ as well as in international studies. ${ }^{4,5}$ In a recently published study, the use of homevisit nursing was associated with a significantly lower risk of hospitalizations related to pressure ulcers. ${ }^{35}$

Furthermore, we found considerable variations between the different language areas, whereby Italian- and Frenchspeaking patients had more intensive treatments compared with German-speaking patients. Similarly, patients residing in the canton of Ticino (Italian-speaking part of Switzerland) were hospitalized more frequently and more often received anticancer drug therapy in the last month(s) of life. ${ }^{15,16}$ In a recently published Swiss study regarding health care costs at the end-of-life, considerable differences were found between the different language areas even after extensive analysis of a variety of individual and further regional characteristics. ${ }^{36}$ We, therefore, suggest that cultural aspects have an important influence on the treatment intensity in Switzerland due to dissimilar expectations and preferences of patients, family members and health care providers.

Considering patient-related characteristics, the intensity of treatment decreased almost linearly with increasing age in our cohort even after adjustment for comorbidities. A decrease in intensive cancer treatment with increasing age at the end-of-life was documented previously. ${ }^{3-5}$ The same was also found in a previous Swiss and US study regarding the use of chemotherapy. ${ }^{16,37}$ Levinsky et $\mathrm{al}^{38}$ have found a decrease in Medicare expenditures with increasing age in the last year of life, after adjustment for several influencing factors such as sex, place and cause of death, mainly due to lower intensity of medical care with increasing age. In contrast to foregoing analysis, we did not find a sex-specific difference in the intensity of treatment. ${ }^{3-5}$

In a multinomial regression analysis, intensive treatment was more likely in patients with lung cancer and less likely in patients with prostate cancer, which is in line with Canadian findings. ${ }^{4}$ However, CIs for all cancer types are rather wide and need to be interpreted with caution. Further research is, therefore, needed to clarify the impact of cancer type on health care utilization measures such as transitions.

In the last 6 months of life, $90 \%$ of cancer patients of our cohort had at least one transition with $87 \%$ being hospitalized, and $>13 \%$ even had a burdensome transition. These are among the highest proportions published so far. In a large cohort study using administrative and registry data on the utilization and costs at the end-of-life, between $69.9 \%$ (Germany) and $88.7 \%$ (Belgium) of elderly patients with cancer were hospitalized at least once in the last 6 months of life. ${ }^{27}$ The proportion of cancer patients with at least one transition between care settings in the last 3 months of death amounted to $53 \%-69 \%$ in four European countries. ${ }^{17}$ In Australia, the median number of hospital admissions (5 vs. 3) and the median number of days in hospital (34 vs. 30) were higher in cancer decedents when compared with non-cancer decedents in their last year of life. ${ }^{39}$ This is comparable with our analysis resulting in a median of two (acute only) hospital admissions in the last 6 months of life with a median length of stay of 31 days. A previous Swiss study on the treatment of adult cancer patients from 2006 to 2008 with at least one hospitalization in their final month of life revealed that patients spent a median of 22 days in an acute hospital in the last 3 months of life, with a median of two hospitalizations. ${ }^{15}$ Transitions, especially hospitalizations at the end-of-life, can be very distressing. They may lead to discontinuity of care and to a loss of information between patient and health care providers, ending up in decreased quality of care at the end-of-life. ${ }^{23,40}$ Therefore, transitions have previously been proposed as indicators for quality of end-of-life care. ${ }^{41}$

In the subanalysis, excluding the cancer decedents who lived in one of the four cantons with hospice availability, the treatment intensity as well as further health care utilization measures were slightly higher compared with the total study population of cancer decedents. Similarly, cancer decedents who resided in regions with a higher availability of hospice services were shown to receive less intensive care at the endof-life in the USA. ${ }^{3}$ This is also in line with a previous study that found a decreased risk of in-hospital death in regions with greater hospice availability and use. ${ }^{42}$ However, differences between our cohorts are rather small and further research is, therefore, needed.

In this study, 2,710 (26.4\%) of all decedents died of cancer in the year 2014. Lung cancer was the leading cause of cancer death. Our data correspond with previous findings on cancer 
research. According to the Organization for Economic Cooperation and Development, ${ }^{43}$ cancer accounted for $25 \%$ of all deaths in 2013, whereby lung cancer was the main cause of cancer mortality. Cancer accounted for $26.2 \%$ of all deaths in Switzerland according to the Swiss Federal Statistical Office. ${ }^{1}$ Hence, our data can be regarded as representative for the whole Swiss population.

\section{Strengths and limitations}

The analysis of this study is based on claims and census data of a sizable cohort, representing almost one-fifth of all Swiss decedents. The data cover a broad range of highly reliable and comprehensive information on end-of-life care. However, this is a retrospective study looking at patients with a known date of death. In most cases, however, the date of death cannot be foreknown, even though cancer has one of the most predictable courses of disease. Nevertheless, two studies comparing health care utilization and costs showed very similar results when comparing their prospectively and retrospectively collected data. ${ }^{34,44}$

Unfortunately, we were not able to distinguish patients whose death was preceded by a clinical state characterized by metastatic cancer and slow deterioration before death from those who died from complications of cancer treatment at an early (but not late) stage. ${ }^{45}$

Although our intensity measures have not been formally validated, they were repeatedly used in other studies as well as by the American Society of Clinical Oncology. The quality of this set of end-of-life intensity measures was, therefore, regarded as good. ${ }^{20}$ Furthermore, among others, ICU admission has been found to be relatively robust and stable in terms of hospital end-of-life treatment intensity measure. ${ }^{46}$ Further research is, however, needed regarding the definition of quality end-of-life care indicators as well as the time trends of treatment intensity. This would enable researchers to better quantify the ratio between appropriate and inappropriate cancer treatments in future studies. Moreover, a more detailed analysis of the association between treatment intensity and the density of different types of specialists and primary care physicians in the ambulatory setting might be useful in explaining the regional differences in the treatment patterns of cancer patients. ${ }^{47,48}$

This study cannot judge the quality of care provided to patients at the end-of-life. The indicators for intensity can only be used as red flags to identify regions or groups of patients with potential challenges concerning the coordination of care at the end-of-life. ${ }^{22}$ Since the study looks at health care utilization in the last months of life - independently of the reason for use - the utilization might not be related to cancer treatment. Additionally, influencing variables, such as the stage, histology of the disease or patients' preferences, could not be taken into account.

\section{Implications}

This study has important implications related to the health care system. A higher density of home care nurses was associated with a decrease in treatment intensity at the end-of-life in our analysis. In Switzerland, considerable regional variations regarding the health services supply at the end-of-life exist, ranging from regions with a comprehensive supply of palliative care, including mobile palliative care teams, to regions with hardly any offering. According to the National Palliative Care Strategy 2013-2015, ${ }^{26}$ palliative care is not yet available for all patients in need. But palliative care was recently found to decrease the risk of hospital admission $(\mathrm{OR}=0.21,95 \% \mathrm{CI}: 0.18-0.26)$ and in-hospital mortality $(\mathrm{OR}=0.03,95 \% \mathrm{CI}: 0.02-0.04)$ in Italy. ${ }^{49}$ In addition, studies have shown that early use of palliative care may, result in prolonged life expectancy and less pain in dying patients. ${ }^{8-10}$ Last but not least, better coordination and discharge planning may help reduce end-of-life health care intensity. ${ }^{50}$ Besides the strengthening of advanced care planning conversations, a closer link between curative therapy and palliative care services is warranted. ${ }^{51,52}$ Additionally, linking patient-provider communication and outcomes might be helpful in developing evidence-based interventions in cancer care. ${ }^{53}$ International evidence demonstrated that the costs of introduction of comprehensive palliative care services may pay off. ${ }^{54}$ In light of our results as well as of international study findings, a denser supply of nursing services and a better coordination of care are urgently needed.

There is an ongoing discussion regarding the intensity of treatment at the end-of-life in highly industrialized countries such as Switzerland. Many people are concerned that particularly older cancer patients are overtreated with chemotherapy. This is especially true for a country such as Switzerland with one of the highest life expectancy worldwide. ${ }^{55}$ Our data show that treatment intensity substantially decreases with increasing age. Transparency concerning health care utilization is important in order to learn from each other to improve care at the end-of-life in cancer patients. There is a huge variety of health care systems and no two are alike. However, as many notably industrialized countries aim at reducing hospitalizations and intensive treatments at the end-of-life, comparisons between countries may help to identify similarities and differences in treatment intensity 
and its underlying causes. The use of similar methodologies and definitions (i.e., regarding the definition of treatment intensity) to evaluate different health care delivery systems across geographic areas and time periods is thus needed. Quantification of cross-country variations in end-of-life care can help guide policymakers with the implementation of culturally and linguistically adapted strategies regarding prevention, early detection or cancer treatment in regions with highest cancer type-specific mortality. ${ }^{56}$

\section{Conclusion}

Swiss cancer patients in the last months of life experience a considerable number of transitions and intensive treatments. There is reason to fear that these care processes may not be in accordance with patient preferences and current best practice in end-of-life care. This study contributes to the ongoing discussion on coordination of medical care at the end-of-life in Swiss cancer patients. It indicates that factors such as density per type of health care provider, the cultural context and other nonclinical patient characteristics may contribute to disparities in the management of those patients. Increased care coordination and timely communication between patients, families and health care professionals about the goals of care might be helpful to reduce unwarranted transitions and intensity of care at the end-of-life.

\section{Acknowledgments}

The authors are grateful to the Swiss Federal Statistical Office for providing them the opportunity to use data on the final cause of death. The authors also thank Sonja Wehrle and Mikaël Thomas for their helpful support in coding in-patient treatments and Annette Jamieson for her critical review of the manuscript.

\section{Disclosure}

The authors report no conflicts of interest in this work.

\section{References}

1. Bundesamt für Statistik [Swiss Federal Statistical Office]. Todesursachen des Jahres; 2014 [Causes of death in 2014]. https://www.bfs. admin.ch/bfs/de/home/statistiken/gesundheit.assetdetail.40496.html. Accessed November 15, 2016. German.

2. Townsend N, Wilson L, Bhatnagar P, Wickramasinghe K, Rayner M, Nichols M. Cardiovascular disease in Europe: epidemiological update 2016. Eur Heart J. 2016;37(42):3232-3245.

3. Earle CC, Neville BA, Landrum MB, Ayanian JZ, Block SD, Weeks JC. Trends in the aggressiveness of cancer care near the end of life. $J$ Clin Oncol. 2004;22(2):315-321.

4. Ho TH, Barbera L, Saskin R, Lu H, Neville BA, Earle CC. Trends in the aggressiveness of end-of-life cancer care in the universal health care system of Ontario, Canada. J Clin Oncol. 2011;29(12): 1587-1591.
5. Langton JM, Blanch B, Drew AK, Haas M, Ingham JM, Pearson S-A. Retrospective studies of end-of-life resource utilization and costs in cancer care using health administrative data: a systematic review. Palliat Med. 2014;28(10):1167-1196.

6. Bosshard G, Nilstun T, Bilsen J, et al. Forgoing treatment at the end of life in 6 European countries. Arch Intern Med. 2005;165(4):401-407.

7. Wright AA, Keating NL, Ayanian JZ, et al. Family perspectives on aggressive cancer care near the end of life. JAMA. 2016;315(3):284-292.

8. Connor SR, Pyenson B, Fitch K, Spence C, Iwasaki K. Comparing hospice and nonhospice patient survival among patients who die within a three-year window. J Pain Symptom Manage. 2007;33(3):238-246.

9. Hamano J, Yamaguchi T, Maeda I, et al. Multicenter cohort study on the survival time of cancer patients dying at home or in a hospital: does place matter? Cancer. 2016;122(9):1453-1460.

10. Temel JS, Greer JA, Muzikansky A, et al. Early palliative care for patients with metastatic non-small-cell lung cancer. $N$ Engl $J$ Med. 2010;363(8):733-742.

11. Matter-Walstra KW, Achermann R, Rapold R, et al. Delivery of health care at the end of life in cancer patients of four Swiss cantons: a retrospective database study (SAKK 89/09). BMC Cancer. 2014;14:306.

12. Bähler C, Signorell A, Reich O. Health care utilisation and transitions between health care settings in the last 6 months of life in Switzerland. PLoS One. 2016;11(9):e0160932.

13. Glasziou P, Straus S, Brownlee S, et al. Evidence for underuse of effective medical services around the world. Lancet. 2017;390(10090):169-177.

14. Brownlee S, Chalkidou K, Doust J, et al. Evidence for overuse of medical services around the world. Lancet. 2017;390(10090):156-168.

15. Matter-Walstra KW, Achermann R, Rapold R, et al. Days spent in acute care hospitals at the end of life of cancer patients in four Swiss cantons: a retrospective database study (SAKK 89/09). Eur J Cancer Care (Engl). Epub 2016 Feb 9.

16. Matter-Walstra KW, Achermann R, Rapold R, et al. Cancer-related therapies at the end of life in hospitalized cancer patients from four Swiss cantons: SAKK 89/09. Oncology. 2015;88(1):18-27.

17. Ko W, Deliens L, Miccinesi G, et al. Care provided and care setting transitions in the last three months of life of cancer patients: a nationwide monitoring study in four European countries. BMC Cancer. 2014;14:960.

18. Alturki A, Gagnon B, Petrecca K, Scott SC, Nadeau L, Mayo N. Patterns of care at end of life for people with primary intracranial tumors: lessons learned. J Neurooncol. 2014;117(1):103-115.

19. Gagnon B, Mayo NE, Hanley J, MacDonald N. Pattern of care at the end of life: does age make a difference in what happens to women with breast cancer? J Clin Oncol. 2004;22(17):3458-3465.

20. Luta X, Maessen M, Egger M, Stuck AE, Goodman D, Clough-Gorr KM. Measuring intensity of end of life care: a systematic review. PLoS One. 2015;10(4): 0123764.

21. Huber CA, Diem P, Schwenkglenks M, Rapold R, Reich O. Estimating the prevalence of comorbid conditions and their effect on health care costs in patients with diabetes mellitus in Switzerland. Diabetes Metab Syndr Obes. 2014; 7:455-465.

22. Earle CC, Park ER, Lai B, Weeks JC, Ayanian JZ, Block SD. Identifying potential indicators of the quality of end-of-life cancer care from administrative data. J Clin Oncol. 2003;21(6):1133-1138.

23. Teno JM, Gozalo PL, Bynum JP, et al. Change in end-of-life care for Medicare beneficiaries: site of death, place of care, and health care transitions in 2000, 2005, and 2009. JAMA. 2013;309(5):470-477.

24. Huber CA, Szucs TD, Rapold R, Reich O. Identifying patients with chronic conditions using pharmacy data in Switzerland: an updated mapping approach to the classification of medications. BMC Public Health. 2013;13:1030.

25. Hosmer DW, Lemeshow S. Applied Logistic Regression. 2nd ed. New York, NY; Chichester: Wiley; 2000. Wilet series in probability and statistics: texts and references section.

26. Bundesamt für Gesundheit und Schweizerische Konferenz der kantonalen Gesundheitsdirektorinnen und -direktoren [Federal Office of Public Health (FOPH) and the Swiss Conference of the Cantonal Ministers of Public Health (CMPH)]. Nationale Strategie Palliative Care 2013-2015; 2012. German. 
27. Bekelman JE, Halpern SD, Blankart CR, et al. Comparison of site of death, health care utilization, and hospital expenditures for patients dying with cancer in 7 developed countries. JAMA. 2016;315(3):272-283.

28. Tang ST, Wu S-C, Hung Y-N, Huang E-W, Chen J-S, Liu T-W. Trends in quality of end-of-life care for Taiwanese cancer patients who died in 2000-2006. Ann Oncol. 2009;20(2):343-348.

29. Gomes B, Calanzani N, Koffman J, Higginson IJ. Is dying in hospital better than home in incurable cancer and what factors influence this? A population-based study. BMC Med. 2015;13:235.

30. GfK Switzerland. Bevölkerungsbefragung Palliative Care [Swiss Survey on Palliative Care]. Forschungsinstitut GfK: Switzerland AG; 2009.

31. Barbera L, Seow H, Sutradhar R, et al. Quality of end-of-life cancer care in Canada: a retrospective four-province study using administrative health care data. Curr Oncol. 2015;22(5):341-355.

32. Braga S, Miranda A, Fonseca R, et al. The aggressiveness of cancer care in the last three months of life: a retrospective single centre analysis. Psychooncology. 2007;16(9):863-868

33. Wright AA, Zhang B, Keating NL, Weeks JC, Prigerson HG. Associations between palliative chemotherapy and adult cancer patients, end of life care and place of death: prospective cohort study. BMJ. 2014;348:g1219.

34. Setoguchi S, Earle CC, Glynn R, et al. Comparison of prospective and retrospective indicators of the quality of end-of-life cancer care. J Clin Oncol. 2008;26(35):5671-5678.

35. Lee HJ, Ju YJ, Park E-C, Kim J, Lee SG. Effects of home-visit nursing services on hospitalization in the elderly with pressure ulcers: a longitudinal study. Eur J Public Health. 2017;27(5):822-826.

36. Panczak R, Luta X, Maessen M, et al. Regional variation of cost of care in the last 12 months of life in Switzerland: small-area analysis using insurance claims data. Med Care. 2017;55(2):155-163.

37. Emanuel EJ, Young-Xu Y, Levinsky NG, Gazelle G, Saynina O, Ash AS. Chemotherapy use among Medicare beneficiaries at the end of life. Ann Intern Med. 2003;138(8):639-643.

38. Levinsky NG, Yu W, Ash AS, et al. Influence of age on Medicare expenditures and medical care in the last year of life. JAMA. 2001;286(11):1349-1355.

39. Rosenwax LK, McNamara BA, Murray K, McCabe RJ, Aoun SM, Currow DC. Hospital and emergency department use in the last year of life: a baseline for future modifications to end-of-life care. Med $J$ Aust. 2011;194(11):570-573.

40. Morrison RS, Penrod JD, Cassel JB, et al. Cost savings associated with US hospital palliative care consultation programs. Arch Intern Med. 2008;168(16):1783-1790.

41. Perrels AJ, Fleming J, Zhao J, et al. Place of death and end-of-life transitions experienced by very old people with differing cognitive status: retrospective analysis of a prospective population-based cohort aged 85 and over. Palliat Med. 2014;28(3):220-233.
42. Pritchard RS, Fisher ES, Teno JM, et al. Influence of patient preferences and local health system characteristics on the place of death. $J$ Am Geriatr Soc. 1998;46(10):1242-1250.

43. Organisation for Economic Co-operation and Development. Health at a Glance 2015: OECD Indicators; 2015. Available from: http://dx.doi. org/10.1787/health_glance-2015-en. Accessed November 7, 2017.

44. Pyenson B, Connor S, Fitch K, Kinzbrunner B. Medicare cost in matched hospice and non-hospice cohorts. J Pain Symptom Manage. 2004;28(3):200-210.

45. Alturki A. Patterns of Care at end of Life for People with Primary Intracranial Tumors: Lessons Learned [thesis]. Montreal, QC: Department of Epidemiology, Biostatistics and Occupational Health; 2013.

46. Barnato AE, Farrell MH, Chang C-CH, Lave JR, Roberts MS, Angus DC. Development and validation of hospital "end-of-life" treatment intensity measures. Med Care. 2009;47(10):1098-1105.

47. Engel-Nitz NM, Alemayehu B, Parry D, Nathan F. Differences in treatment patterns among patients with castration-resistant prostate cancer treated by oncologists versus urologists in a US managed care population. Cancer Manag Res. 2011;3:233-245.

48. Ankuda CK, Petterson SM, Wingrove P, Bazemore AW. Regional variation in primary care involvement at the end of life. Ann Fam Med. 2017;15(1):63-67.

49. Scaccabarozzi G, Limonta F, Amodio E. Hospital, local palliative care network and public health: how do they involve terminally ill patients? Eur J Public Health. 2017;27(1):25-30.

50. Brown JR, Chang C-H, Zhou W, MacKenzie TA, Malenka DJ, Goodman DC. Health system characteristics and rates of readmission after acute myocardial infarction in the United States. J Am Heart Assoc. 2014;3(3):e000714.

51. Gawande A. Quantity and quality of life: duties of care in life-limiting illness. JAMA. 2016;315(3):267-269.

52. Ferris FD, Bruera E, Cherny N, et al. Palliative cancer care a decade later: accomplishments, the need, next steps-from the American Society of Clinical Oncology. J Clin Oncol. 2009;27(18):3052-3058.

53. Sheldon LK, Hong F, Berry D. Patient-provider communication data: linking process and outcomes in oncology care. Cancer Manag Res. 2011;3:311-317.

54. Fassbender K, Fainsinger R, Brenneis C, Brown P, Braun T, Jacobs P. Utilization and costs of the introduction of system-wide palliative care in Alberta, 1993-2000. Palliat Med. 2005;19(7):513-520.

55. Organisation for Economic Co-operation and Development. Health at a glance. 2013. Life Expectancy at Birth; 2013. Available from: https://www.oecd.org/els/health-systems/Health-at-a-Glance-2013.pdf. Accessed November 09, 2017

56. Wheeler SB, Basch E. Translating cancer surveillance data into effective public health interventions. JAMA. 2017;317(4):365-367.
Cancer Management and Research

\section{Publish your work in this journal}

Cancer Management and Research is an international, peer-reviewed open access journal focusing on cancer research and the optimal use of preventative and integrated treatment interventions to achieve improved outcomes, enhanced survival and quality of life for the cancer patient. The manuscript management system is completely online and includes

\section{Dovepress}

a very quick and fair peer-review system, which is all easy to use. Visit http://www.dovepress.com/testimonials.php to read real quotes from published authors. 